\title{
The association between hypoxia inducible factor 1 subunit alpha gene rs2057482 polymorphism and cancer risk: a meta- analysis
}

\author{
Li-Fang Wu ${ }^{1+}$, Gui-Ping X ${ }^{2+}$, Qing Zhao ${ }^{1}$, Li-Jing Zhou ${ }^{1}$, Ding Wang ${ }^{1}$ and Wei-Xian Chen ${ }^{1 *}$
}

\begin{abstract}
Background: The rs2057482 polymorphism in the hypoxia inducible factor 1 subunit alpha (HIF1A) gene has been reported to be associated with a risk of several types of cancer, but this association has not yet been definitively confirmed. We performed this meta-analysis to determine whether rs2057482 is associated with overall cancer risk.

Methods: The PubMed, Embase, and Web of Science databases were searched for the potential studies about the association between the rs2057482 and cancer risk. The data of genotype frequencies in cases with cancer and controls were extracted from the selected studies. Odds ratios (ORs) and the corresponding 95\% confidence intervals ( $\mathrm{Cls}$ ) were calculated to determine the strength of the associations.

Results: The meta-analysis showed an association between the rs2057482 polymorphism and overall cancer risk. However, a stratified analysis of ethnicity did not show any significant association between rs2057482 and cancer risk in the Asian population.

Conclusions: The rs2057482 polymorphism was associated with decreased overall cancer risk, based on the currently available studies. However, this conclusion needs verification by further well-designed epidemiology studies that examine different cancer types and more subjects.
\end{abstract}

Keywords: HIF1A, Cancer, Meta-analysis, Polymorphism, rs2057482

\section{Background}

Hypoxia inducible factor 1 (HIF1) is a transcription factor that coordinates the response to hypoxia in cells and tissues [1]. HIF1 is a heterodimeric protein consisting of HIF1A and HIF1B subunits. The HIF1A subunit is induced by hypoxia and forms an active transcription inducer with HIF1B [2]. HIF1 activation promotes the expression of several hypoxia-adaptation genes, including those involved in the biological processes of angiogenesis, erythropoiesis, cell proliferation, and apoptosis [3, 4].

Hypoxia is a common issue in tumor tissues [5]. HIF1A regulates cellular adaptation to hypoxia and

\footnotetext{
* Correspondence: chenweixian75@163.com

${ }^{\dagger}$ Li-Fang Wu and Gui-Ping Xu contributed equally to this work.

${ }^{1}$ Department of Laboratory Medicine, The Second Affiliated Hospital of

Chongqing Medical University, Chongqing 400010, China

Full list of author information is available at the end of the article
}

promotes tumor development [6-8]. HIF1A expression increases in various types of cancer, such as breast, prostate, and colon cancer [9], and a high expression of HIF1A in a tumor indicates poor patient prognosis [10]. The relapse-free survival time is significantly lower for the hepatocellular carcinoma patients with high expression of HIF1A than for patients with low expression [11].

The rs2057482 polymorphism is located in the $3^{\prime}$ untranslated region (3'-UTR) region of the HIF1A gene. The SNP has been widely explored for its relationship with cancer risk [12-18]. We performed this metaanalysis to provide a more accurate assessment and obtain a comprehensive understanding of the relationship between rs2057482 and cancer risk.

(c) The Author(s). 2019 Open Access This article is distributed under the terms of the Creative Commons Attribution 4.0 International License (http://creativecommons.org/licenses/by/4.0/), which permits unrestricted use, distribution, and reproduction in any medium, provided you give appropriate credit to the original author(s) and the source, provide a link to the Creative Commons license, and indicate if changes were made. The Creative Commons Public Domain Dedication waiver (http://creativecommons.org/publicdomain/zero/1.0/) applies to the data made available in this article, unless otherwise stated. 


\section{Methods}

\section{Search strategy}

Three databases (PubMed, Embase, and Web of Science) were retrieved up to September 24, 2019, using the following keywords: "hypoxia inducible factor 1 subunit alpha or HIF1A," "polymorphism or variant or mutation or SNP," and "cancer or carcinoma or tumor." We also checked the Ensembl web site for potential studies (http://asia.ensembl.org/Homo_sapiens/Variation).

\section{Inclusion and exclusion criteria}

The inclusion criteria were:

1. The study is about the relationship between rs2057482 and cancer risk.

2. The study is a case-control study or cohort study.

3. The study must contain sufficient genotype data for the meta-analysis.

4. The study is published in English.

We excluded reviews, meta-analyses, and abstracts.

\section{Data extraction}

The data from the selected studies were extracted by two authors separately. The extracted data were the following: first author; publication year; country or region where the study conducted; control source; genotype methods; and genotype frequencies.

\section{Quality score}

We evaluated the quality of these included studies by scoring each study based on the case and control source, number of subjects, and Hardy-Weinberg equilibrium (Additional file 1: Table S1) [19].

\section{Statistical analysis}

Statistical analyses were carried out using the Stata software (Version 12.0, Stata Corporation, College Station, TX). ORs and 95\%Cls were calculated to evaluate the strength of the association between the rs2057482 polymorphism and cancer risk. $P$ values $<0.05$ were considered statistically significant. This meta-analysis used five genetic models: the allele (T vs. C), homozygote (TT vs. $\mathrm{CC}$ ), heterozygote (CT vs. $\mathrm{CC}$ ), dominant (TT $+\mathrm{CT}$ vs. $\mathrm{CC}$ ), and recessive models (TT vs. $\mathrm{CT}+\mathrm{CC}$ ). We also conducted stratified analysis of ethnicity; however, only one study was about the Caucasian population, so we have only shown results for the Asian population. In addition, only one study was retrieved about each type of cancer, so we did not conduct a stratified analysis of cancer type. We measured the heterogeneity with the parameter $\mathrm{I}^{2}$ and the $P$-value with the Chi-squared test [20]. When $\mathrm{I}^{2}<50 \%$ or $P>0.10$, the fixed model was used [21]; otherwise, a random model was used [22]. Sensitivity analyses were performed by removing one study each time [23]. Publication bias was determined using the Egger and Begg tests [24, 25].

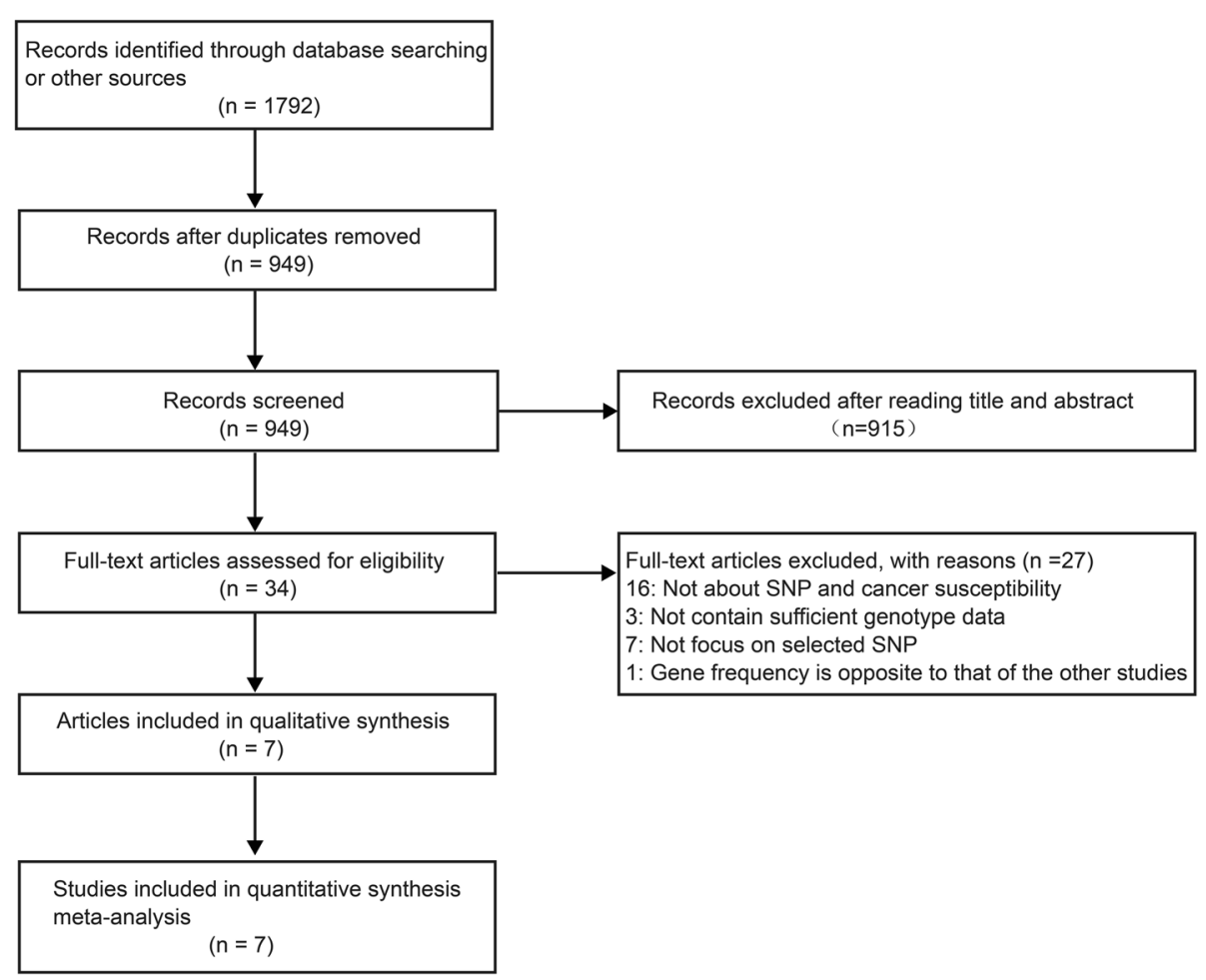

Fig. 1 The flow diagram of included/excluded studies 
Table 1 Characteristics of the studies included in the meta-analysis

\begin{tabular}{|c|c|c|c|c|c|c|}
\hline First author & Year & $\begin{array}{l}\text { Country/ } \\
\text { Region }\end{array}$ & Ethnicity & Cancer type & $\begin{array}{l}\text { Genotyping } \\
\text { method }\end{array}$ & Control source \\
\hline Lee (12) & 2008 & Korea & Asian & breast cancer & SNP-ITM assays & $\mathrm{PB}$ \\
\hline Qin (13) & 2011 & China & Asian & $\mathrm{RCC}$ & Taqman & $\mathrm{HB}$ \\
\hline Li (14) & 2012 & China & Asian & prostate cancer & Taqman & $H B$ \\
\hline Wang (15) & 2016 & China & Asian & PDAC & DNA sequence & PB \\
\hline Yamamoto (16) & 2016 & Japan & Asian & lung cancer & Taqman & $\mathrm{HB}$ \\
\hline Gregory (17) & 2016 & USA & Mix & $\mathrm{NHL}$ & $\begin{array}{l}\text { Fluidigm Dynamic } \\
\text { 96.96 } \text { Array }^{\text {TM }} \text { assay }\end{array}$ & $\mathrm{HB}$ \\
\hline Martina (18) & 2018 & Czech & Caucasian & MM & Taqman & $\mathrm{HB}$ \\
\hline
\end{tabular}

RCC, renal cell carcinoma; PDAC, pancreatic ductal adenocarcinoma; NHL: non-Hodgkin lymphoma; MM: multiple myeloma; PB, population-based; $\mathrm{HB}$, hospital-based

\section{Results}

\section{Characteristics of the studies}

The process used to select target articles is shown in Fig. 1. The database searches identified 949 studies after removing duplicate records. A further check of the titles and abstracts excluded 915 studies. We read the full text of the remaining 34 studies and ultimately selected 7 studies for the meta-analysis. The included studies were conducted between 2008 and 2018; five studies were about the Asian population, one was about the Caucasian population, and one was about a mixed population. The characteristics of these studies are shown in Table 1. The genotype frequencies are listed in Table 2.

\section{Meta-analysis}

In this meta-analysis, the overall analysis under the dominant genetic model showed a significant association between the rs2057482 polymorphism and a decreased risk of cancer (Table 3 and Fig. 2, TT + CT vs. CC: OR, 0.89, 95\% CI, 0.81-0.98, $P=0.017)$. However, the stratified analysis of ethnicity did not indicate an association between rs2057482 and cancer risk in the Asian population in any of the genetic models (Table 3 ). We only synthesized the results if two or more studies were available, so the results for the Caucasian population were not shown.

\section{Sensitivity analysis}

Sensitivity analyses were performed using the metainf command. Exclusion of the Qin2011 study led to a different result in the allele model, and exclusion of the Wang2016 study led to a different result in the dominant model (Fig. 3 and Additional file 1: Table S2). We also preformed sensitivity analyses in Asian populations. Exclusion of the Qin2011 study led to a different result in the allele model (Additional file 1: Table S3). These results suggest that our results were not stable in these models.

\section{Publication bias}

Egger and Begg tests carried out to detect potential publication bias revealed no publication bias in this metaanalysis (Table 4).

\section{Discussion}

HIF1A plays a central role in tumor adaptation to hypoxia $[26,27]$. HIF1A mediates the hypoxic adaptation of tumor cells and tissues in multiple ways [28]. For example,

Table 2 HIF1A rs2057482 polymorphism genotype distribution and allele frequency in cases and controls

\begin{tabular}{|c|c|c|c|c|c|c|c|c|c|c|c|c|c|c|}
\hline & \multicolumn{8}{|c|}{ Genotype(N) } & \multicolumn{4}{|c|}{ Allele frequency $(\mathrm{N})$} & \multirow[t]{3}{*}{ HWE } & \multirow[t]{3}{*}{ Score } \\
\hline & \multicolumn{4}{|l|}{ Case } & \multicolumn{4}{|c|}{ Control } & \multicolumn{2}{|l|}{ Case } & \multicolumn{2}{|c|}{ Control } & & \\
\hline & Total & $\mathrm{CC}$ & $\mathrm{CT}$ & $\pi$ & Total & CC & $C T$ & $\pi$ & C & T & C & T & & \\
\hline Lee 2008 (12) & 1150 & 691 & 415 & 44 & 1048 & 611 & 396 & 41 & 1797 & 503 & 1618 & 478 & 0.018 & 11 \\
\hline Qin 2011 (13) & 620 & 388 & 196 & 36 & 623 & 393 & 201 & 29 & 972 & 268 & 987 & 259 & 0.613 & 12 \\
\hline Li 2012 (14) & 662 & 418 & 212 & 32 & 716 & 428 & 241 & 47 & 1048 & 276 & 1097 & 335 & 0.103 & 12 \\
\hline Wang 2016 (15) & 410 & 301 & 69 & 40 & 490 & 302 & 154 & 34 & 671 & 149 & 758 & 222 & 0.022 & 10 \\
\hline Yamamoto 2016 (16) & 462 & 302 & 138 & 22 & 379 & 244 & 121 & 14 & 742 & 182 & 609 & 149 & 0.834 & 11 \\
\hline Gregory 2016 (17) & 180 & 125 & 49 & 6 & 528 & 369 & 147 & 12 & 299 & 61 & 885 & 171 & 0.554 & 11 \\
\hline Martina 2018 (18) & 275 & 225 & 47 & 3 & 219 & 176 & 39 & 4 & 497 & 53 & 391 & 47 & 0.297 & 10 \\
\hline
\end{tabular}




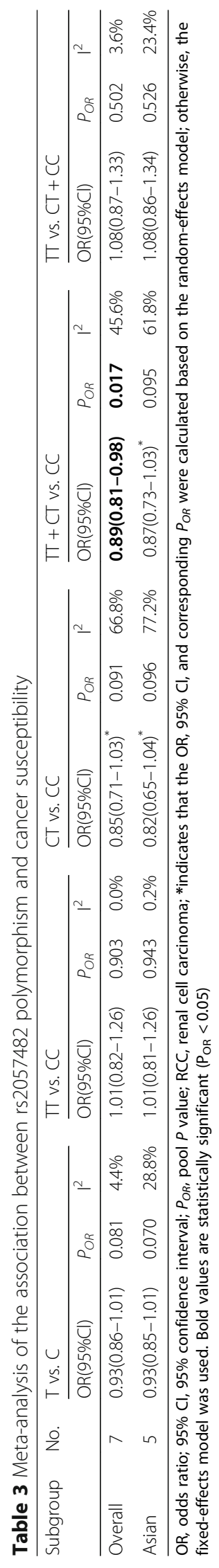




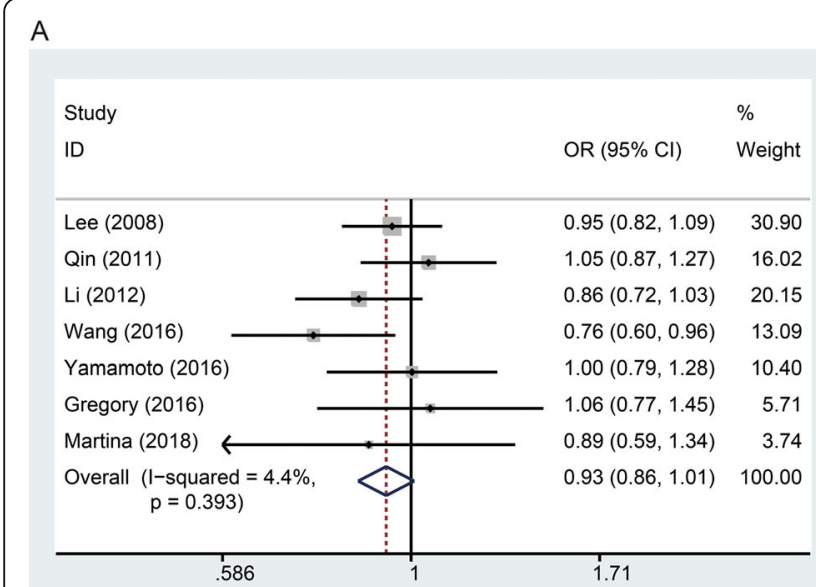

C

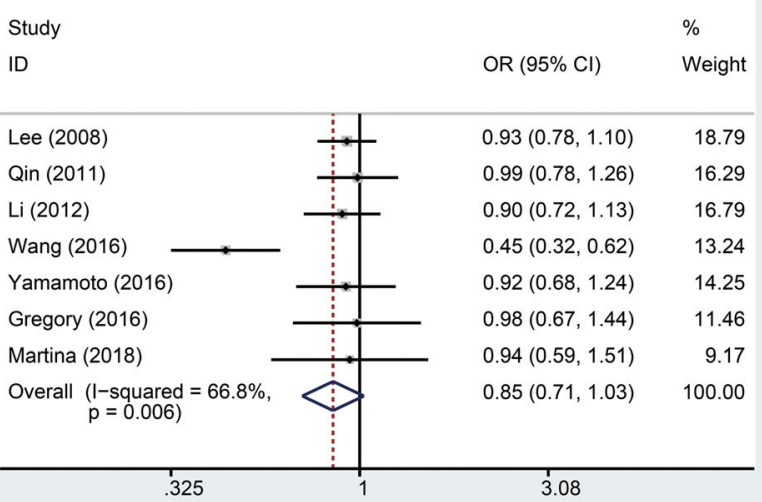

$E$

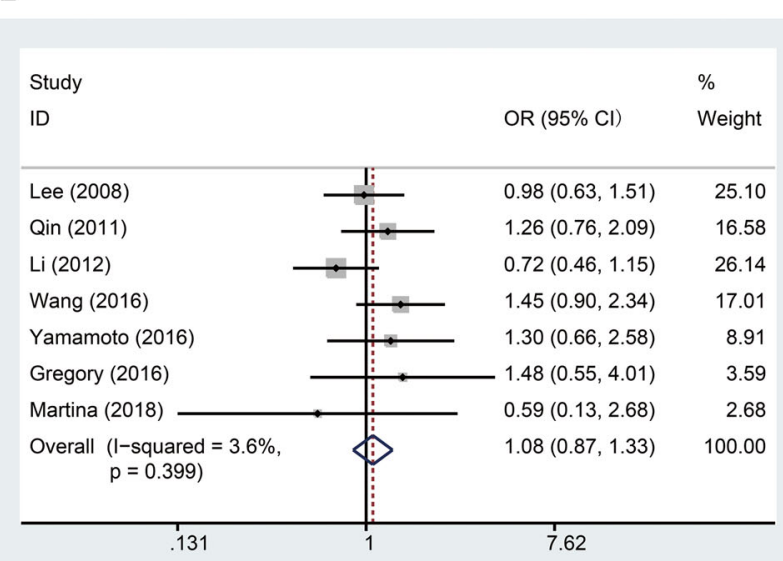

B

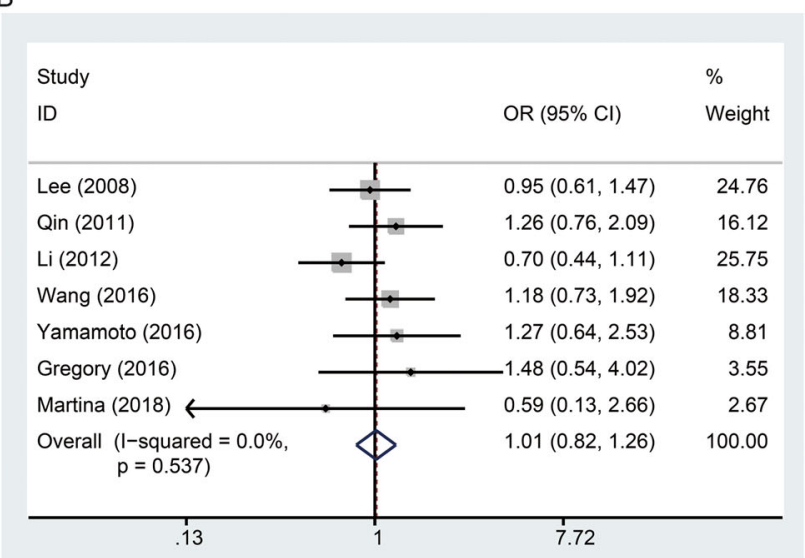

D

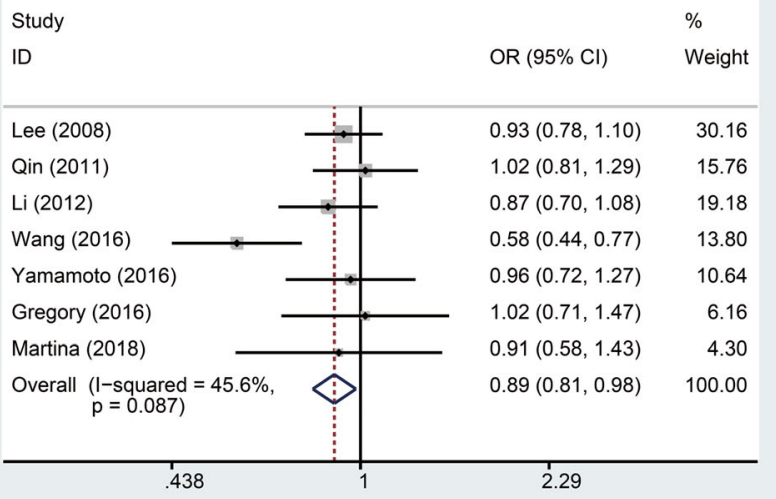

Fig. 2 Meta-analysis of the association between rs2057482 and risk of cancer a: allele model; b: homozygous model; c: heterozygous model; D: dominant model; E: recessive model. The squares and horizontal lines correspond to the study specific OR and 95\% Cl. The area of the squares reflects the weight. The diamond represents the summary OR and $95 \% \mathrm{Cl}$. The random-effects model was used for the heterozygous genetic model, and fixed-effects models were used for other genetic models.

angiogenesis is an important aspect of cancer progression, and HIF1A contributes to tumor angiogenesis by upregulating vascular endothelial growth factor (VEGF) and other proangiogenic factors [29, 30]. HIF1A also increases the expression of multiple enzymes involved in glycolysis, which further aids tumor cell growth and proliferation [31-34]. In addition, HIF1A promotes autophagy by altering the expression of BCL2/adenovirus E1B $19 \mathrm{kDa}$ 


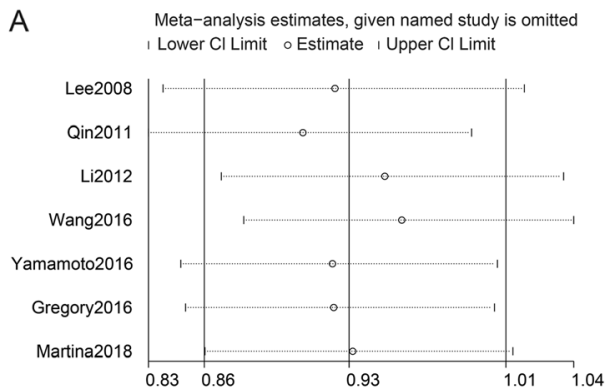

B Meta-analysis estimates, given named study is omitted Lower Cl Limit oEstimate । Upper Cl Limit

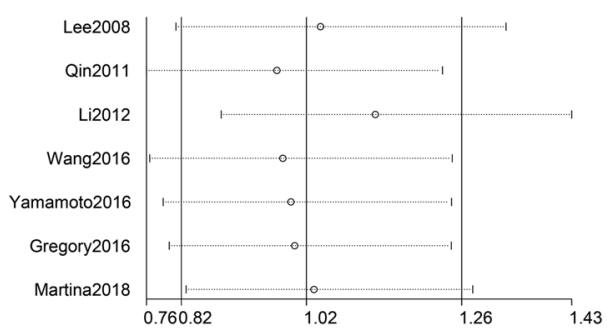

C Meta-analysis random-effects estimates, given named study is omitted Lower Cl Limit oEstimate । Upper CI Limit

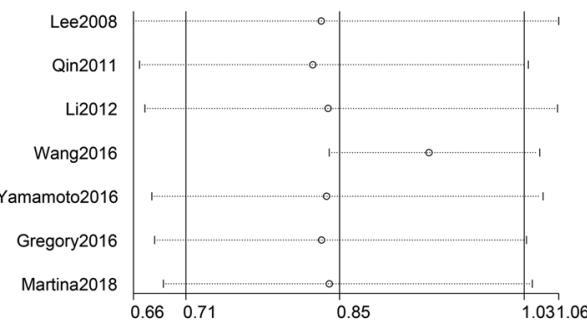

D Meta-analysis estimates, given named study is omitted I Lower Cl Limit oEstimate । Upper Cl Limit

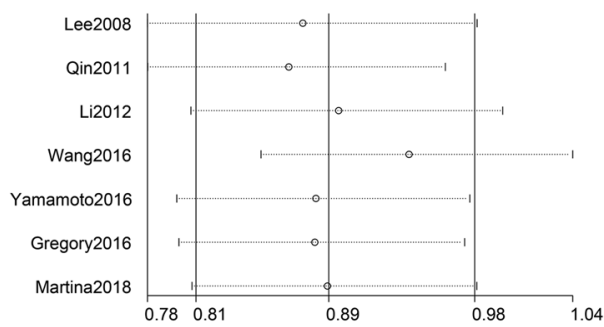

E Meta-analysis estimates, given named study is omitted Lower Cl Limit oEstimate, Upper Cl Limit

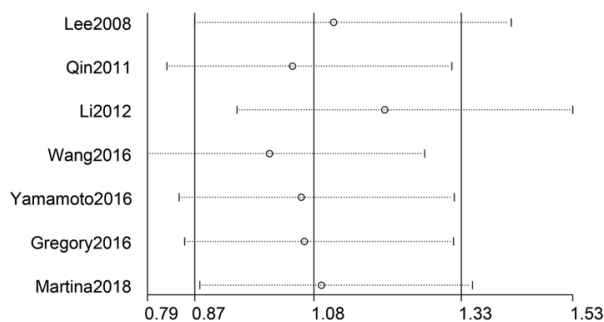

Fig. 3 Sensitivity analyses between rs2057482 polymorphism and risk of cancer a: allele model; $\mathbf{b}$ : homozygous model; $\mathbf{c}$ : heterozygous model; $\mathbf{d}$ : dominant model; e: recessive model. The random-effects model was used for the heterozygous genetic model, and fixed-effects models were used for other genetic models.

protein-interacting protein 3 (BNIP3), which is part of a stress adaptation mechanism that promotes tumor cell survival and avoids cell death [35, 36]. Many studies have reported associations between $H I F 1 A$ polymorphisms and the risks of various types of cancer, including bladder, oral, and colorectal cancers, head and neck squamous cell carcinoma, and renal cell carcinoma [37-40].

The HIF1A gene has many SNPs, but we focused on rs2057482 for the following reasons: First, the relationship between rs2057482 and cancer risk has been reported in previous epidemiology studies [12-18]. Second, in the 1000 Genomes Project Phase 3, minor allele frequencies of rs2057482 are greater than 10\% in most populations (Additional file 1: Table S4). Third, the selected SNP may have important biological functions, according to previous reports.

The rs2057482 polymorphism is located in the 3'UTR of HIF1A. Many researchers have hypothesized that this polymorphism may be located near the microRNA binding site and that it affects the expression of HIF1A by binding HIF1A to the microRNA [13, 15-18]. Wang et al. reported that rs2057482 may affect the expression of HIF1A by microRNA 199a [15]. Gregory et al., based on silico analyses with the miRNA-SNP analytic tool TargetScan 5.2, suggested that the $\mathrm{T}$ allele of HIF1A rs2057482 created new microRNA binding sites for microRNA 196a-2 [17].

The rs2057482 polymorphism has been reported to associate with the occurrence and prognosis of several kinds of cancer [41-44]. For example, this polymorphism was found to decrease the risk of non-Hodgkin's lymphoma associated with central nervous system acquired immune deficiency syndrome [17]. An association has also been reported between rs2057482 polymorphism and prognosis of early-stage lung cancer patients after surgery [45]. In addition, the recurrence rate of

Table 4 Publication bias analysis

\begin{tabular}{|c|c|c|c|c|}
\hline \multirow{2}{*}{$\begin{array}{l}\text { Genetic } \\
\text { model }\end{array}$} & \multicolumn{3}{|c|}{ Egger's test } & \multirow{2}{*}{$\begin{array}{l}\text { Begg's test } \\
P\end{array}$} \\
\hline & $\bar{t}$ & $95 \% \mathrm{Cl}$ & $P$ & \\
\hline T vs. C & -0.03 & $-3.644 \sim 3.573$ & 0.981 & 1.000 \\
\hline Tा vs. CC & 0.23 & $-2.671 \sim 3.207$ & 0.824 & 0.764 \\
\hline CT vs. CC & -0.60 & $-7.483 \sim 4.660$ & 0.576 & 0.548 \\
\hline$T T+C T$ vs. $C C$ & -0.28 & $-5.559 \sim 4.470$ & 0.791 & 0.764 \\
\hline TT vs. $C T+C C$ & 0.09 & $-3.138 \sim 3.371$ & 0.930 & 1.000 \\
\hline
\end{tabular}


hepatocellular carcinoma is lower in CT + TT carrier patients than in CC carrier patients [11].

Our meta-analysis revealed that rs2057482 decreased the overall cancer risk in the dominant genetic model. We hypothesize that the carrier of the T allele $(\mathrm{CT}+\mathrm{TT})$ creates a new microRNA binding site. Binding leads to decreased expression of HIF1A, thereby reducing the risk of cancer. However, this conclusion is made based on only seven types of tumor (breast, lung, prostate cancer, pancreatic ductal adenocarcinoma, renal cell carcinoma, nonHodgkin's lymphoma, and multiple myeloma); therefore, we suggest that the relationship between rs2057482 and more types of cancer should be investigated in further studies.

The current meta-analysis has the following limitations that should be recognized. First, the number of studies contained in the meta-analysis is limited, and the majority of the study populations were Asians. The genomic effect of this SNP could be ethnicity specific, so this prevalence of Asian subjects may have biased the results for overall cancer risk. The present study results therefore only provide meaningful information for Asian populations, and we recommend additional research on the risk of cancer and rs2057482 in Caucasian and other populations in the future. Second, only one study was included for each cancer type, so we did not conduct a stratified analysis based on cancer type. Each type of cancer may have a different underlying genomic mechanism, so more studies on rs2057482 and cancer risk are needed for each type of cancer. Finally, the mechanism by which this SNP affects tumor risk is still unclear and needs further exploration.

\section{Conclusions}

Our meta-analysis suggests that the rs205782 polymorphism of the HIF1A gene significantly decreases the overall cancer risk, based on the synthesis results of the included studies. This conclusion should be further verified by additional studies that include more subjects and cancer types.

\section{Supplementary information}

Supplementary information accompanies this paper at https://doi.org/10. 1186/s12885-019-6329-2.

Additional file 1: Table S1. Quality score assessment. Table S2. Sensitivity analyses for rs2057482 polymorphism and cancer susceptibility. Table S3. Sensitivity analyses for rs2057482 polymorphism and cancer susceptibility in Asian population. Table S4. MAFs of rs 2057482 polymorphism in the populations from the 1000 Genomes Project Phase 3.

\section{Abbreviation}

3'-UTR: three prime untranslated region; BNIP3: BCL2/adenovirus E1B 19 kDa protein-interacting protein 3; Cl: confidence interval; $\mathrm{HB}$ : hospital-based; HIF1: hypoxia inducible factor 1; HWE: Hardy-Weinberg equilibrium; MAF: minor allele frequency; MM: multiple myeloma; NHL: non-Hodgkin lymphoma; OR: odds ratio; PB: population-based; PDAC: pancreatic ductal adenocarcinoma; RCC: renal cell carcinoma; SNP: single nucleotide polymorphism; VEGF: vascular endothelial growth factor

\section{Acknowledgements}

Not applicable.

\section{Authors' contributions}

Conceived and designed the meta-analysis:WXC,GPX, LFW. Searched the databases: LFW, QZ, LJZ. Analyzed the data: GPX,DW. Revised the manuscript: WXC, GPX. Wrote the paper: LFW. All authors have read and approved the final submitted manuscript.

\section{Funding}

Publication costs are funded by funding from the National Natural Science Foundation of China (Grant No. 81601826).

\section{Availability of data and materials}

All data generated or analysed during this study are included in this published article and its supplementary information files.

Ethics approval and consent to participate

Not applicable.

Consent for publication

Not applicable.

\section{Competing interests}

The authors declare they have no conflicts of interest.

\section{Author details}

${ }^{1}$ Department of Laboratory Medicine, The Second Affiliated Hospital of Chongqing Medical University, Chongqing 400010, China. ${ }^{2}$ Transfusion Department, The Second Affiliated Hospital of Chongqing Medical University, Chongqing, China.

Received: 13 July 2019 Accepted: 4 November 2019 Published online: 19 November 2019

\section{References}

1. Wang GL, Semenza GL. Purification and characterization of hypoxiainducible factor 1. J Biol Chem. 1995;270(3):1230-7. https://doi.org/10.1074/ jbc.270.3.1230

2. Baldewijns MM, van Vlodrop IJ, Vermeulen PB, Soetekouw PM, van Engeland $M$, de Bruine AP. VHL and HIF signalling in renal cell carcinogenesis. J Pathol. 2010;221(2):125-38. https://doi.org/10.1002/path.2689.

3. Semenza GL. Targeting HIF-1 for cancer therapy. Nat Rev Cancer. 2003;3(10): 721-32. https://doi.org/10.1038/nrc1187

4. Tanimoto K, Yoshiga K, Eguchi H, Kaneyasu M, Ukon K, Kumazaki T, Oue N, Yasui W, Imai K, Nakachi K, et al. Hypoxia-inducible factor-1alpha polymorphisms associated with enhanced transactivation capacity, implying clinical significance. Carcinogenesis. 2003;24(11):1779-83. https://doi.org/10. 1093/carcin/bgg132.

5. Semenza GL. The hypoxic tumor microenvironment: a driving force for breast cancer progression. Biochim Biophys Acta. 2016;1863(3):382-91. https://doi.org/10.1016/j.bbamcr.2015.05.036

6. Leek RD, Talks KL, Pezzella F, Turley H, Campo L, Brown NS, Bicknell R, Taylor M, Gatter KC, Harris AL. Relation of hypoxia-inducible factor-2 alpha (HIF-2 alpha) expression in tumor-infiltrative macrophages to tumor angiogenesis and the oxidative thymidine phosphorylase pathway in human breast cancer. Cancer Res. 2002;62(5):1326-9.

7. Akakura N, Kobayashi M, Horiuchi I, Suzuki A, Wang J, Chen J, Niizeki H, Kawamura K, Hosokawa M, Asaka M. Constitutive expression of hypoxiainducible factor-1alpha renders pancreatic cancer cells resistant to apoptosis induced by hypoxia and nutrient deprivation. Cancer Res. 2001;61(17):6548-54.

8. Hayashi Y, Yokota A, Harada H, Huang G. Hypoxia/pseudohypoxia-mediated activation of hypoxia-inducible factor-1alpha in cancer. Cancer Sci. 2019; 110(5):1510-7. https://doi.org/10.1111/cas.13990.

9. Zhong H, De Marzo AM, Laughner E, Lim M, Hilton DA, Zagzag D, Buechler $P$, Isaacs WB, Semenza GL, Simons JW. Overexpression of hypoxia-inducible 
factor 1alpha in common human cancers and their metastases. Cancer Res. 1999:59(22):5830-5.

10. Baba Y, Nosho K, Shima K, Irahara N, Chan AT, Meyerhardt JA, Chung DC, Giovannucci EL, Fuchs CS, Ogino S. HIF1A overexpression is associated with poor prognosis in a cohort of 731 colorectal cancers. Am J Pathol. 2010; 176(5):2292-301. https://doi.org/10.2353/ajpath.2010.090972.

11. Guo X, Li D, Chen Y, An J, Wang K, Xu Z, Chen Z, Xing J. SNP rs2057482 in HIF1A gene predicts clinical outcome of aggressive hepatocellular carcinoma patients after surgery. Sci Rep. 2015;5:11846. https://doi.org/10.1038/srep11846.

12. Lee JY, Choi JY, Lee KM, Park SK, Han SH, Noh DY, Ahn SH, Kim DH, Hong YC, Ha E et al: Rare variant of hypoxia-inducible factor-1alpha (HIF-1A) and breast cancer risk in Korean women. Clinica chimica acta; international journal of clinical chemistry 2008, 389(1-2):167-170. https://doi.org/10.1016/j.cca.2007.12.005.

13. Qin C, Cao Q, Ju X, Wang M, Meng X, Zhu J, Yan F, Li P, Ding Q, Chen J, et al. The polymorphisms in the VHL and HIF1A genes are associated with the prognosis but not the development of renal cell carcinoma. Ann Oncol. 2012;23(4):981-9. https://doi.org/10.1093/annonc/mdr325.

14. Li P, Cao Q, Shao PF, Cai HZ, Zhou H, Chen JW, Qin C, Zhang ZD, Ju XB, Yin $\mathrm{CJ}$. Genetic polymorphisms in HIF1A are associated with prostate cancer risk in a Chinese population. Asian journal of andrology. 2012;14(6):864-9. https://doi.org/10.1038/aja.2012.101

15. Wang $X$, Ren $H$, Zhao T, Ma W, Dong J, Zhang S, Xin W, Yang S, Jia L, Hao J. Single nucleotide polymorphism in the microRNA-199a binding site of HIF1A gene is associated with pancreatic ductal adenocarcinoma risk and worse clinical outcomes. Oncotarget. 2016;7(12):13717-29. https://doi.org/ 10.18632/oncotarget.7263.

16. Yamamoto Y, Kiyohara C, Ogata-Suetsugu S, Hamada N, Nakanishi Y. Association between genetic polymorphisms involved in the hypoxia-inducible factor pathway and lung cancer risk: a case-control study in Japan. Asia-Pacific journal of clinical oncology. 2017;13(3):234-42. https://doi.org/10.1111/ajco.12640.

17. Peckham-Gregory EC, Thapa DR, Martinson J, Duggal P, Penugonda S, Bream JH, Chang PY, Dandekar S, Chang SC, Detels R, et al. MicroRNA-related polymorphisms and non-Hodgkin lymphoma susceptibility in the multicenter AIDS cohort study. Cancer Epidemiol. 2016:45:47-57. https://doi.org/10.1016/j.canep.2016.09.007.

18. Almasi M, Besse L, Brozova L, Jarkovsky J, Bezdekova R, Pour L, Minarik J, Kessler P, Pavlicek P, Roziakova L, et al. Selected genetic polymorphisms associated with hypoxia and multidrug resistance in monoclonal Gammopathies patients. Klinicka onkologie : casopis Ceske a Slovenske onkologicke spolecnosti. 2018; 31(3):213-29. https://doi.org/10.14735/amko2018213.

19. Tian X, Dai S, Sun J, Jiang S, Jiang Y. Association between TP53 Arg72Pro polymorphism and leukemia risk: a meta-analysis of 14 case-control studies. Sci Rep. 2016;6. https://doi.org/10.1038/srep24097.

20. Higgins JP, Thompson SG. Quantifying heterogeneity in a meta-analysis. Stat Med. 2002;21(11):1539-58. https://doi.org/10.1002/sim.1186.

21. Mantel N, Haenszel W. Statistical aspects of the analysis of data from retrospective studies of disease. J Natl Cancer Inst. 1959;22(4):719-48.

22. DerSimonian R, Laird N. Meta-analysis in clinical trials. Control Clin Trials. 1986;7(3):177-88.

23. Steichen T. METANINF: Stata module to evaluate influence of a single study in meta-analysis estimation. Stat Softw Components. 2001.

24. Begg CB, Mazumdar M. Operating characteristics of a rank correlation test for publication bias. Biometrics. 1994;50(4):1088-101.

25. Egger M, Davey Smith G, Schneider M, Minder C. Bias in meta-analysis detected by a simple, graphical test. Bmj. 1997;315(7109):629-34.

26. Nagaraju GP, Bramhachari PV, Raghu G, El-Rayes BF. Hypoxia inducible factor-1alpha: its role in colorectal carcinogenesis and metastasis. Cancer Lett. 2015;366(1):11-8. https://doi.org/10.1016/..canlet.2015.06.005.

27. Zhang H, Lu H, Xiang L, Bullen JW, Zhang C, Samanta D, Gilkes DM, He J, Semenza GL. HIF-1 regulates CD47 expression in breast cancer cells to promote evasion of phagocytosis and maintenance of cancer stem cells. Proc Natl Acad Sci U S A. 2015;1 12(45):E6215-23. https://doi.org/10.1073/pnas.1520032112.

28. Ajdukovic J. HIF-1--a big chapter in the cancer tale. Exp Oncol. 2016;38(1):9-12.

29. Forsythe JA, Jiang BH, lyer NV, Agani F, Leung SW, Koos RD, Semenza GL. Activation of vascular endothelial growth factor gene transcription by hypoxia-inducible factor 1. Mol Cell Biol. 1996;16(9):4604-13. https://doi.org/10.1128/mcb.16.9.4604.

30. Kelly BD, Hackett SF, Hirota K, Oshima Y, Cai Z, Berg-Dixon S, Rowan A, Yan Z, Campochiaro PA, Semenza GL. Cell type-specific regulation of angiogenic growth factor gene expression and induction of angiogenesis in nonischemic tissue by a constitutively active form of hypoxia-inducible factor 1. Circ Res. 2003;93(11):1074-81. https://doi.org/10.1161/01.res. $0000102937.50486 .1 \mathrm{~b}$.

31. Unwith S, Zhao H, Hennah L, Ma D. The potential role of HIF on tumour progression and dissemination. Int J Cancer. 2015;136(11):2491-503. https:// doi.org/10.1002/ijc.28889.

32. Yuneva M: Finding an "Achilles' heel" of cancer: the role of glucose and glutamine metabolism in the survival of transformed cells. Cell cycle (Georgetown, Tex) 2008, 7(14):2083-2089. https://doi.org/10.4161/cc.7.14.6256.

33. Gess B, Hofbauer KH, Deutzmann R, Kurtz A. Hypoxia up-regulates triosephosphate isomerase expression via a HIF-dependent pathway. Pflugers Archiv : European journal of physiology. 2004;448(2):175-80. https:// doi.org/10.1007/s00424-004-1241-1.

34. Lu S, Gu X, Hoestje S, Epner DE: Identification of an additional hypoxia responsive element in the glyceraldehyde-3-phosphate dehydrogenase gene promoter. Biochim Biophys Acta 2002, 1574(2):152-156. https://doi. org/10.1016/s0167-4781(01)00359-1.

35. Soni S, Padwad YS: HIF-1 in cancer therapy: two decade long story of a transcription factor. Acta oncologica (Stockholm, Sweden) 2017, 56(4): 503-515. https://doi.org/10.1080/0284186x.2017.1301680.

36. Walls KC, Ghosh AP, Ballestas ME, Klocke BJ. Roth KA: bcl-2/adenovirus E1B 19-kd interacting protein 3 (BNIP3) regulates hypoxia-induced neural precursor cell death. J Neuropathol Exp Neurol. 2009;68(12):1326-38. https:// doi.org/10.1097/NEN.0b013e3181c3b9be.

37. Fransen $K$, Fenech M, Fredrikson M, Dabrosin C, Soderkvist P. Association between ulcerative growth and hypoxia inducible factor-1alpha polymorphisms in colorectal cancer patients. Mol Carcinog. 2006;45(11):83340. https://doi.org/10.1002/mc.20209.

38. Ollerenshaw M, Page T, Hammonds J, Demaine A. Polymorphisms in the hypoxia inducible factor-1alpha gene (HIF1A) are associated with the renal cell carcinoma phenotype. Cancer Genet Cytogenet. 2004;153(2):122-6. https://doi.org/10.1016/j.cancergencyto.2004.01.014.

39. Li XD, Zi H, Fang C, Zeng XT. Association between HIF1A rs11549465 polymorphism and risk of prostate cancer: a meta-analysis. Oncotarget. 2017;8(27):44910-6. https://doi.org/10.18632/oncotarget.16489.

40. Kang MJ, Jung SA, Jung JM, Kim SE, Jung HK, Kim TH, Shim KN, Yi SY, Yoo K, Moon IH. Associations between single nucleotide polymorphisms of MMP2, VEGF, and HIF1A genes and the risk of developing colorectal cancer. Anticancer Res. 2011;31(2):575-84.

41. Munoz-Guerra MF, Fernandez-Contreras ME, Moreno AL, Martin ID, Herraez B, Gamallo C. Polymorphisms in the hypoxia inducible factor 1-alpha and the impact on the prognosis of early stages of oral cancer. Ann Surg Oncol. 2009;16(8):2351-8. https://doi.org/10.1245/s10434-009-0503-8.

42. Nadaoka J, Horikawa Y, Saito M, Kumazawa T, Inoue T, Narita S, Yuasa T, Satoh S, Nishiyama H, Ogawa O, et al. Prognostic significance of HIF-1 alpha polymorphisms in transitional cell carcinoma of the bladder. Int J Cancer. 2008;122(6):1297-302. https://doi.org/10.1002/ijc.23256.

43. Cai FF, Xu C, Pan X, Cai L, Lin XY, Chen S, Biskup E. Prognostic value of plasma levels of HIF-1a and PGC-1a in breast cancer. Oncotarget. 2016;7(47): 77793-806. https://doi.org/10.18632/oncotarget.12796.

44. Hoffmann AC, Mori R, Vallbohmer D, Brabender J, Klein E, Drebber U, Baldus $\mathrm{SE}$, Cooc J, Azuma M, Metzger R et al: High expression of HIF1a is a predictor of clinical outcome in patients with pancreatic ductal adenocarcinomas and correlated to PDGFA, VEGF, and bFGF. Neoplasia (New York, NY) 2008, 10(7):674-679. https://doi.org/10.1593/neo.08292.

45. Liu B, Liu Q, Song Y, Li X, Wang Y, Wan S, Zhang Z, Su H: Polymorphisms of HIF1A gene are associated with prognosis of early stage non-small-cell lung cancer patients after surgery. Medical oncology (Northwood, London, England) 2014, 31(4):877. https://doi.org/10.1007/s12032-014-0877-8.

\section{Publisher's Note}

Springer Nature remains neutral with regard to jurisdictional claims in published maps and institutional affiliations. 